\title{
Veröffentlichungen
}

der Vereinigung der Deutschen Staatsrechtslehrer

\section{Die Grenzen der Verfassungsgerichtsbarkeit}

\section{Die Gestaltung des Polizei- und Ordnungs- rechts in den einzelnen Besatzungszonen}

\author{
Berich te \\ von

\section{Erich Kaufmann Martin Drath} \\ Hans Julius Wollf Otto Gönnenwein
}

Verhandlangen der Tagung der Deutschen Staatorecbtslehrer en Mînchen am 20. und 21. Oktober 1950

Mit einem Auszug aus der Anesprache

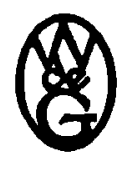

\section{Berlin 1952 \\ Walter de Gruyter \& Co.}


Arabiv-Nr. 248952

Ste und Druel : Buchknaet, Borlis W 35 